\title{
VIDAS NUAS NO ESTADO DE EXCEÇÃO: ENSAIO SOBRE A VIOLÊNCIA POLICIAL NO RIO DE JANEIRO
}

\author{
EMPTY LIFES IN THE STATE OF EXCEPTION \\ ESSAY ABOUT POLICE VIOLENCE IN RIO DE JANEIRO
}

\author{
Daniel Machado Gomes ${ }^{i}$ \\ Robson Cesar Durãoii \\ Tiago da Silva Cicilioiii
}

\begin{abstract}
Resumo: O objetivo do presente ensaio é demonstrar a condição de vida nua do cidadão no Rio de Janeiro, onde se percebe a radicalização das características do fenômeno nomeado por Giorgio Agamben como estado de exceção, devido à legitimação da violência do Estado exercida à margem da legalidade. Neste contexto, os autos de resistência são um meio de garantir a impunidade dos agentes públicos que exercem a força policial. O texto traz dados estatísticos da violência policial no Brasil e no estado do Rio de Janeiro, além de explicar as categorias do pensamento de Agamben, interrelacionando-as com a realidade fluminense. $O$ estudo empregou o método bibliográfico de pesquisa com a utilização de livros e periódicos, tendo como marco teórico as ideias filosóficas do pensador contemporâneo Giorgio Agamben. Conclui-se que o Rio de Janeiro vive uma situação de anomia na qual a lei perdeu força e a força é exercida fora da lei, privando o cidadão de seus direitos e garantias fundamentais.
\end{abstract}

\footnotetext{
i Doutor em Filosofia pelo IFCS, da UFRJ (2015). Mestre em Ciências Juridico-Civilísticas pela Universidade de Coimbra, Portugal (2003).. É líder do grupo de pesquisa Lei, Justiça e Direitos Humanos no qual coordena o projeto Genealogia dos Direitos Humanos.

ii Mestre em Direito pela Universidade Católica de Petrópolis (UCP); Pós-Graduado em Direito Público com ênfase em Gestão Pública pela Faculdade de Direito Damásio; Pós-Graduando em Ciências Criminais pela Pontifícia Universidade Católica de Minas Gerais.

iii Bacharelando em Direito pela UCP/RJ (2019.2); associado à ANDHEP (Associação Nacional de Direitos Humanos, Pesquisa e Pós-Graduação). Pesquisador bolsista do CNPq no grupo de iniciação científica Lei, Justiça e Direitos Humanos do Centro de Ciências Jurídicas da UCP/RJ no qual pesquisa: Memória e Direitos Humanos.
} 
Palavras-chave: Estado de Exceção. Vida Nua. Autos de Resistência. Letalidade Policial. Violência Estatal.

Abstract: The objective of this essay is to demonstrate the empty life condition of Rio de Janeiro's citizens, where is perceived the radicalization of the characteristics of the phenomenon named by Giorgio Agamben as state of exception, due to the legitimacy of state violence exercised outside legality. In this context, acts of resistance are the means to ensure the impunity of the public agents that exercise law enforcement. The text provides statistical data on police violence in Brazil and the state of Rio de Janeiro, besides, it explains Agamben's categories of thought, interrelating them with fluminenses' reality. The study used the bibliographic research method with the use of books and periodicals, having as theoretical framework the philosophical ideas of the contemporary thinker Giorgio Agamben's. It is concluded that Rio de Janeiro lives in an anomie situation in which the law has lost it's force and the force is exercised outside the law, depriving citizens of their fundamental rights and guarantees.

Keywords: State of Exception. Empty Lifes. Acts of Resistance. Police Lethality. State Violence.

\section{INTRODUÇÃO}

O emprego de força policial à margem da legalidade expõe a condição de vida nua do cidadão no Rio de Janeiro, onde se percebe a radicalização das características do fenômeno nomeado de estado de exceção por Giorgio Agamben, pensador contemporâneo que estuda as relações entre poder e sociedade. Diante deste cenário, a principal questão do presente artigo é a coisificação da pessoa humana, que se vê reduzida à mera existência biológica, sendo privada de direitos pela banalização do emprego da força estatal. O estudo utilizou o método de pesquisa bibliográfico em livros e periódicos, tendo como marco teórico as ideias filosóficas de Agamben. O trabalho se justifica pela crescente onda de mortes causadas pela polícia no Rio, que está associada à impunidade dos agentes públicos. Assim, o texto tem o objetivo de expor estatísticas sobre a violência policial, relacionando estes números com os conceitos de vida nua e de estado de exceção. 
O presente ensaio está dividido em três partes; a primeira seção visa demonstrar com dados quantitativos a crescente letalidade da polícia no Brasil, além de contextualizar e analisar o uso dos autos de resistência que estabelecem a exclusão da ilicitude, quando o agente público pratica $\mathrm{o}$ ato em legítima defesa ou para vencer a resistência. $O$ artigo investiga também estatísticas de homicídios cometidos pela polícia no Rio de Janeiro, que revelam o padrão das vítimas: homens jovens, predominantemente negros, que vivem em comunidades e em áreas tidas como marginalizadas. O que deixa claro a negativa posição de liderança do Estado Brasileiro na lista de países com o maior número de homicídios, com uma média de cinco pessoas por dia mortas pela polícia. Essa espécie de execução sumária velada é uma herança da ditadura militar que ganhou novos contornos na atualidade, ainda mais pelo fato de os governos acreditarem que só a força arbitrária pode combater a criminalidade. Isso demonstra que o Estado tende a estimular e regulamentar a execução dos inimigos do poder público, criando meios para assegurar sua própria impunidade.

Na segunda parte, o texto pretende evidenciar quantas investigações criminais de homicídios decorrentes de intervenção policial chegaram ao Poder Judiciário, conforme os dados da obra. Quando a polícia mata", de Michel Misse, que analisou registros de ocorrência sobre autos de resistência no ano de 2005. Relatou-se que menos da metade dos casos em que houve homicídio nessas intervenções tornaram-se inquéritos policiais. Em 2008, aproximadamente $5 \%$ dos inquéritos policiais foram levados à Justiça Criminal. E, penosamente, 99,2\% desses autos de resistência foram arquivados de plano pelo Parquet. A impunidade dessas ações violentas da polícia no Rio de Janeiro expõe um quadro social que se revela no termo grego zoé, ou o que Agamben chama de vida nua, vinculada à figura do homo sacerdo, Direito Romano arcaico, ou seja, o homem matável (sem configurar homicídio), não politizado e reduzido à inferioridade social e insacrificável.

A última seção visa demonstrar que no estado de exceção a norma jurídica em vigor não tem aplicabilidade, não tem força, ao mesmo tempo em que o Estado produz atos dotados de força, mas sem qualquer conteúdo normativo ou de lei, prevalecendo a efetividade da "força de lei". Esse estado relaciona-se com a ausência de norma jurídica ou a falta de efetividade das normas de direito, que faz com que surja o que Agamben chama de "vida nua". "Vida nua" é uma expressão usada para se referir à experiência da desproteção legal e política daqueles que vivem submetidos à anomia gerada pela exceção. Neste sentido, o estado de exceção faz 
com que o Direito se refira à vida e a inclua em si por meio de sua própria suspensão, surgindo daí a vida nua. Na prática se exclui da tutela jurídica aqueles que se encontram à margem do corpo político, que se assemelha à situação fluminense.

\section{A VIOLÊNCIA ESTATAL LEGITIMADA}

Os Anuários Brasileiros de Segurança Pública relativos ao período de 2014 a 2017 revelam a crescente taxa de mortes resultantes de intervenção policial. Conforme o Anuário de 2016, entre os anos de 2011 a 2015 o Estado brasileiro registrou mais vítimas de mortes violentas intencionais do que na guerra da Síria: aqui foram executadas 279.567 pessoas em contraste com os 256.124 mortos no território sírio. O Anuário de 2017 constatou que 7 (sete) pessoas por hora morreram assassinadas em 2016, havendo 61.283 registros de mortes violentas: um crescimento de $4 \%$ em relação a 2015. No ano de 2016 cresceu 25\% a letalidade das polícias, 4.222 pessoas foram mortas em decorrência de intervenção de policiais civis e militares. Entre 2009 e 2016, 21.892 pessoas perderam suas vidas em ações policiais, destas $99,3 \%$ eram homens, $81,8 \%$ tinham entre 12 e 29 anos e 76,2\% eram negros. O estudo verifica o crescimento da violência no Brasil, o que nos deixa entre os países que mais matam no mundo, assim como entre aqueles que possuem a polícia mais letal.

Sob a ótica de proteção dos direitos humanos, é assustador que exista também um fenômeno de legitimação da violência do Estado pela população brasileira já que, segundo os dados do Anuário Brasileiro de Segurança Pública de 2015, 50\% dos entrevistados concordam com a frase "bandido bom é bandido morto". No ano de 2015 a Câmara dos Deputados fez uma enquete sobre a modificação do procedimento dos autos de resistência por meio da PL 4.471/2012. Para tanto se perguntava: "você concorda com o projeto que cria regras rigorosas para a apuração de mortes e lesões decorrentes de ações de policiais e outros agentes do Estado?". O resultado foi negativo, demonstrando que $72,13 \%$ da sociedade afirma que os "direitos humanos são para humanos direitos", além de revelar a cultura contemporânea que autoriza o Estado a se valer dos chamados autos de resistência (DESARMAMENTO..., 2015).

O procedimento nominado como autos de resistência, de acordo com Sérgio Verani (1996, p. 33), foi criado em 2 de outubro de 1969, pela Superintendência da Polícia do Estado da Guanabara, através da Ordem 
de Serviço no 803, publicada no Boletim de Serviço do dia 21 de novembro de 1969. O objetivo dos autos de resistência é impedir a prisão em flagrante dos policiais quando existirem confrontos que resultarem em lesões corporais ou no óbito dos indivíduos que resistirem à força do Estado. Também são utilizados os autos de resistência em inquéritos nas circunstâncias previstas no art. 292 do Código de Processo Penal brasileiro. A Ordem de Serviço no 803 deve ser compreendida como "regulamentação específica" no estado do Rio de Janeiro, uma vez que é oriunda da interpretação do Código de Processo Penal de 1941. Já o Código de Processo Penal Militar de 1969 traz consigo a previsão dos procedimentos dos autos de resistência (VERANI, 1996).

Misse (2011, p. 28) esclarece que o termo "autos de resistência" origina-se do art. 292 do Código de Processo Penal, combinado com a previsão legal do art. 121 e do art. 233, inciso II, ambos do Código Penal, que preveem a exclusão da ilicitude quando o agente pratica o ato em legítima defesa para "defender-se ou para vencer a resistência". Salientase que a Resolução n 8, de 21 dezembro de 2012, do Conselho de Defesa dos Direitos Humanos, entendeu ser inaceitável classificar "execuções extrajudiciais ou sumárias" como "autos de resistência" ou "resistência seguida de morte" em registros policiais, boletins de ocorrências e inquéritos policiais, devendo tais registros serem consignados com o nome técnico "lesão corporal decorrente de intervenção policial" ou "homicídio decorrente de intervenção policial".

Ao analisar os homicídios praticados por policiais civis e militares nos Estados de Mato Grosso do Sul, do Rio de Janeiro, de São Paulo e de Santa Catarina, o Conselho de Defesa dos Direitos Humanos verificou que entre janeiro de 2010 e junho de 2012 houve 3.086 mortes em confrontos com policiais, sendo 2.986 registradas por meio dos nominados "autos de resistência" ou "resistência seguida de morte" e 100 mortes em ação de policiais civis e militares.

As execuções sumárias dos "inimigos do Estado" neste lapso temporal demostram claramente a coisificação de 2.986 seres humanos cujas mortes não foram devidamente investigadas. Estas "vidas nuas" são o resultado da situação de anomia que atinge paradoxalmente a sociedade tida como democrática e pautada na dignidade humana. Desta forma, revela-se o que Agamben chama de "estado de exceção", um modo de organização política no qual os direitos perdem a força normativa e a força, se desagregados no Direito. 


\section{A VIDA NUA FLUMINENSE}

Sobre os executores que representam o Estado, a Anistia Internacional publicou, no ano de 2015, um relatório sobre os homicídios cometidos pela Polícia Militar, especificamente na cidade do Rio de Janeiro. Entre 2010 e 2013 houve 1.275 homicídios decorrentes de intervenção policial na cidade do Rio de Janeiro, sendo que $99,5 \%$ eram homens, $79 \%$ eram negros e $75 \%$ tinham entre 15 e 29 anos de idade. Neste documento consta que o Estado Brasileiro lidera a lista de países com o maior número de homicídios, enfatizando que no ano de 2012 foram assassinadas 56 mil pessoas.

Destaca-se que os estereótipos dos mortos estão associados aos jovens, predominantemente negros, que vivem em comunidades e em áreas tidas como marginalizadas. Os dados demonstram que no ano de 2012 mais de $50 \%$ das vítimas de homicídios tinham entre 15 e 29 anos e, destes, $77 \%$ eram de cor negra. O relatório estima o número de 1.809 pessoas que foram mortas pelas Polícias Militar e Civil Brasileiras, quando em serviço no ano de 2013, uma média de cinco pessoas mortas pela polícia por dia no Brasil.

Em que pese aos autos de resistência terem sua gênese na ditadura militar, seus ideais desconstroem os direitos do homem, ganham novos contornos e se perpetuam na redemocratização. No caso do estado do Rio de Janeiro, por reflexo da ideologia perpetuada na ditadura militar, esses ideais estão presentes desde o primeiro governo de Leonel de Moura Brizola (1983-1987), e, posteriormente, no governo Moreira Franco (19871991), que implementou o "Plano dos Cem Dias: Metas e Resultados", a fim de acabar com a violência no estado do Rio de Janeiro. Para tanto, de acordo com professora Francisca Vergínio Soares: "Moreira Franco acreditava apenas na força arbitrária para combater a criminalidade" (SOARES, 2002 , p. 181). Em certa medida, tanto no primeiro quanto no segundo governo de Brizola (1991-1995), surge o ideal de direitos humanos na atividade policial. Para Sento-Sé (2002, p.101), a afirmação política do chamado "brizolismo" contribuiu para o deslocamento no debate sobre direitos humanos no Brasil. Todavia, a execução sumária sempre esteve à espreita e, de certa forma, velada na pós-ditadura; sempre houve desde a criação dos autos de resistência a "possibilidade de alguém ou alguma 
coisa cortar a fina linha" da espada de Dâmocles ${ }^{1}$ e assim cortar a dignidade da minoria.

Ao ser eleito governador do estado do Rio de Janeiro, Marcelo Alencar (1995-1999) instituiu a premiação policial conhecida como "gratificação faroeste"2 . Dessa forma, o Estado, mais uma vez, cortou o fio da espada e ceifou os direitos humanos de parcela da população. Neste momento histórico, o Estado regulamentou e estimulou a execução sumária dos inimigos do Poder Público e por meio dos autos de resistência se assegurava a impunidade tutelada pelo Estado.

A pesquisa desenvolvida por Ignácio Cano e outros, "Letalidade da ação policial no Rio de Janeiro: a atuação da Justiça Militar", analisou 301 inquéritos entre os anos de 1993 e 1996, e 295 inquéritos foram arquivados pelo Poder Judiciário a pedido do promotor. Apenas 6 (seis) denúncias viraram processo, sendo que estes crimes não foram cometidos em comunidade ou área de risco, mas, mesmo assim, houve a absolvição dos policiais, a pedido do Ministério Público. O estudo revela que $98 \%$ das ocorrências são arquivadas (CANO et al., 2004).

O professor sociólogo Michel Misse e outros (2013. p. 45), por meio de sua pesquisa "Quando a Polícia Mata", na cidade do Rio de Janeiro, durante o ano de 2005, analisou os 510 registros de ocorrência sobre autos de resistência, nos quais 707 pessoas foram vitimadas de homicídio, sendo que apenas 355 tornaram-se inquéritos policiais. Em 2008, dos 355 inquéritos policiais somente 19 desses casos foram levados à Justiça Criminal. Dos 19 inquéritos policiais que chegaram a ser judicializados, 16 foram encaminhados ao Ministério Público com pedido de arquivamento e, penosamente, 3 (três) casos de ocorrência de autos de resistência foram denunciados ao Poder Judiciário. A pesquisa destaca que no Tribunal de Justiça do Estado do Rio de Janeiro o número de inquéritos policiais de autos de resistência arquivados ou que não tiveram denúncia oferecida alcança a cifra de $99,2 \%$ do total.

\footnotetext{
1 A referência é ao mito grego clássico da Espada de Dâmocles, o qual faz alusão à representação da insegurança de se perder a condição em que o indivíduo se encontra devido a qualquer contingência ou ameaça.

2 Por meio do Decreto $n^{\circ} 21.753 / 95$, a gratificação gerava uma melhoria no salário, variando em um aumento de $10 \%$ a $150 \%$ e, pelo mesmo ato, a possibilidade de receber uma promoção por bravura. Surgiu, a partir de então, o "kit sucesso", implantação de provas ilegais na cena do "crime".
} 
A impunidade das ações violentas da polícia no Rio de Janeiro expõe um quadro social que revela a ausência de linguagem e importância políticas das vítimas que se encontram na posição de mera vida nua, ou seja, de vida natural não politizada. Os gregos possuíam dois termos para exprimir o sentido de vida, zoé indicava o simples fato de viver, algo comum a todos os seres vivos, enquanto a palavra bíos designava a forma ou a maneira de viver própria de um indivíduo ou de um grupo. O conceito de vida nua se aproxima, portanto, da definição de zoé, distanciando-se da qualidade de bios.

Na obra Homo Sacer Giorgio Agamben demonstra que a simples vida natural seria excluída da pólis propriamente dita, permanecendo como mera vida reprodutiva.Agamben vincula a vida nua à figura do "homo sacer" do direito romano arcaico, condição de inferioridade social daquele que qualquer um podia matar impunemente (matabilidade sem configurar homicídio) e que não podia ser objeto de sacrifício, no sentido de que não se poderia tornar oferenda aos deuses (insacrificabilidade). Essa figura traduz-se na ideia de inclusão da vida humana no ordenamento unicamente sob a forma de sua exclusão.

A impunidade da matança e a exclusão do sacrifício configuram, ao mesmo tempo, duas exceções, sendo uma ao direito humano (ius humanum) e outra ao direito divino (ius divinum). No primeiro caso, suspendese a aplicação da lei sobre uma ação que, ordinariamente, seria considerada homicídio. No segundo, retira-se a possibilidade de qualquer morte ritual ou de purificação ritual, excluindo-se do âmbito religioso. "A vida insacrificável e, todavia, matável é a vida sacra" (AGAMBEN, 2010, p.83). Essa dupla exceção não é apenas uma simples analogia da estrutura da exceção soberana, na qual a lei é aplicada ao caso excepcional, retirandose deste. $O$ que define a condição do homo sacer, além da ambivalência do sacro, é essa dupla exclusão e a exposição à violência insacionável (AGAMBEN, 2010, p.84).

O homem sacro é objeto da soberania, pois a vida nua é produto original do poder soberano, permanecendo exposta a um poder de morte irrepreensível. Segundo Agamben (2010, p.87-88), a palavra "sacer" representa, portanto, a vida matável, exposta a uma violência que ultrapassa a seara do direito, ao mesmo tempo em que não corresponde à do sacrifício, estando, desse modo, numa zona de indistinção entre o direito humano e o direito divino. E a decisão soberana, ao suspender a ordem jurídica no estado de exceção, produz no interior deste a vida nua que é essa vida humana matável e insacrificável. 


\section{ESTADO DE EXCEÇÃO EM AGAMBEN}

Para explicar a vida nua, Giorgio Agamben vale-se do estado de exceção, que é uma situação de anomia que reside no centro dos Estados Democráticos de Direito, no qual a lei e a força se encontram dissociadas. No estado de exceção a norma jurídica em vigor não tem aplicabilidade, não tem força, ao mesmo tempo em que o Estado produz atos dotados de força, mas sem qualquer conteúdo normativo e que não são leis. Neste sentido, sob o modelo do estado de exceção, prevalece a efetividade da "força de lei". A menção ao sintagma "força de lei" faz referência a decretos que podem ser promulgados pelo Poder Executivo em situações que deveriam ser excepcionais e que, apesar de não serem leis em sentido formal, possuem poder de obrigar.

A palavra anomia é formada pela soma do prefixo "a", indicando negação, mais o vocábulo "nomia" que significa norma. Logo anomia tanto pode designar a ausência de norma jurídica, quanto a falta de efetividade das normas de direito. Agamben associa a anomia ao estado de exceção, caracterizando-o como um estado de coisas "fora da lei" que explica a realidade política contemporânea nas democracias ocidentais europeias e nos Estados Unidos. Segundo Chueiri (2005, p.p. 141-142), para Agamben ou a lei existe e vigora, mas não se aplica por carência de força, ou a lei não existe formalmente e já tem força. Assim, Chueiri entende que Agamben chama a atenção para o fato de que no estado de exceção há força de lei sem lei.

No primeiro capítulo da obra "Estado de Exceção", Agamben apresenta um panorama da evolução da exceção na modernidade, demonstrando que há nele uma exacerbação dos poderes do Executivo em relação ao Legislativo. Esses atos normativos do Executivo que não são leis, mas detêm força, decorrem da ampliação dos poderes governamentais, dos plenos poderes que caracterizam o estado de exceção, notadamente, quando é atribuído ao Poder Executivo a autoridade para promulgar decretos com força de lei. Neste contexto, ocorre "a abolição provisória da distinção entre Poder Legislativo, Executivo e Judiciário" (AGAMBEN, 2004, p. 19).

Em Agamben, o estado de exceção está intimamente associado à vida nua, um conceito cunhado para se referir à experiência da desproteção legal e política daqueles que vivem submetidos à anomia gerada pela exceção - algo inerente à cultura política do Ocidente. Neste sentido, o es- 
tado de exceção faz com que o Direito se refira à vida e a inclua em si por meio de sua própria suspensão, surgindo daí a vida nua. Na modernidade a exceção cria uma anomia que independe de formalização constitucional ou legislativa, mas que serve de paradigma de facto da atual política dominante. Na prática, exclui-se da tutela jurídica aqueles que se encontram à margem do corpo político, isto é, os que estão na simples condição de vida nua.

Apesar de atingir todo o Ocidente contemporâneo, a concepção de vida puramente biológica se manifesta de modo acentuado em países subdesenvolvidos como o Brasil, nos quais dificuldades econômicas favorecem a marginalização e a exclusão de direitos, assim como a atual situação do fluminense.

\section{CONCLUSÃO}

Nesse artigo foi abordado a crescente e legitimada violência do Estado por parte dos seus agentes policiais, civis e militares, quando em serviço. Foi constatado que esse aumento é decorrente da redução da pessoa à condição de vida nua e da utilização de meios para legitimar as ações e garantir a impunidade do do estado, como os autos de resistência, que são abusivamente utilizados nos registros policiais, boletins de ocorrências e inquéritos policiais.

Na primeira parte do artigo foi visto que o crescimento da violência no Brasil se relaciona com o fenômeno da legitimação do uso da força do Estado através dos "autos de resistência" e da coisificação da pessoa. Nesse giro, o trabalho permitiu observar a definição e contextualização do termo autos de resistência, o que justifica a ascendente letalidade da polícia. Como os autos de resistência possibilitam a exclusão da ilicitude em determinados casos, os agentes policiais utilizam-se desse termo para garantir a impunidade nas situações de lesão corporal ou homicídio decorrentes de intervenção policial, ou para execuções extrajudiciais.

$\mathrm{O}$ artigo investigou os relatórios que buscavam descrever quantativamente casos de homicídios cometidos pela polícia no Rio de Janeiro. Foi percebido que o Brasil lidera a lista de países com o maior número de homicídios cometidos por policiais e o padrão dessas vítimas é de homens jovens, predominantemente negros, que vivem em comunidades 
em áreas tidas como marginalizadas, o que está diretamente ligado à herança da ditadura militar, em que há execução sumária velada e o pensamento predominante para combater a criminalidade é exclusivamente a força arbitrária - uma tendência de estímulo e regulamentação da execução dos inimigo do Poder Público.

O texto evidenciou o número irrisório de investigações criminais de homicídios decorrentes de intervenção policial provenientes de autos de resistência que terminaram no Poder Judiciário, isto é, em 2005, menos da metade tornaram-se inquéritos policiais. Dos inquéritos, em 2008, aproximadamente $5 \%$ foram levados à Justiça Criminal. E, penosamente, só $0,8 \%$ não foram arquivados de pleno pelo Parquet. Essa impunidade expõe um quadro social que Agamben chama de vida nua.

Por fim, o texto relacionou a concepção do estado de exceção e da vida nua em Agamben. Foi apontado que o estado de exceção é a abolição provisória da distinção entre os três poderes (Legislativo, Executivo e Judiciário). E que, dessa maneira, a norma jurídica em vigor não tem aplicabilidade ao mesmo tempo em que o Estado produz atos dotados de força, mas não são leis, sem qualquer conteúdo normativo. A vida nua surge nessas circunstancias, por ser a experiência da desproteção legal e política daqueles que vivem submetidos à anomia gerada pela exceção.

Por todo exposto, percebeu-se que o estado do Rio de Janeiro vive uma situação de anomia, e esse estado de exceção reduz os fluminenses a uma vida nua, tanto pela coisificação das pessoas cujas mortes não foram, e não são, devidamente investigadas, quanto pela impunidade da violência praticada pelos policiais e da cultura que a legitima.

\section{REFERÊNCIAS}

AGAMBEN, Giorgio. Homo Sacer: o poder soberano e a vida nua. Trad. de Henrique Burigo. Belo Horizonte: Editora UFMG, 2010.

Estado de exceção. Trad. Iraci D. Poleti. 2. ed. São Paulo: Boitempo, 2004.

ANISTIA INTERNACIONAL. Você matou meu filho!: homicídios cometidos pela Polícia Militar na cidade do Rio de Janeiro. Rio de Janeiro, 2015. Disponível em: < https://anistia.org.br/wp-content/uploads/2015/07/Noce-matou-meufilho_Anistia-Internacional-2015.pdf>. Acesso em: 07 nov. 2018. 
ANUÁRIO Brasileiro de Segurança Pública. Disponível em: http://www.forumseguranca.org.br/wp-content/uploads/2017/01/ Anuario_Site_27-01-2017-RETIFICADO.pdf. Acesso em 01.08.2018.

Disponível em: <http://www.forumseguranca.org.br/storage/8_ anuario_2014_20150309.pdf>. Acesso em: 1 ago. 2018.

Disponível em: <http://ww.forumseguranca.org.br/storage/9_ anuario_2015.retificado_.pdf>. Acesso em: 1 ago. 2018.

Disponível em: <http://www.forumseguranca.org.br/storage/10_ anuario_site_18-11-2016-retificado.pdf>. Acesso em: 1 ago. 2018.

. Disponível em: <http://www.forumseguranca.org.br/wp-content/ uploads/2017/01/Anuario_Site_27-01-2017-RETIFICADO.pdf >. Acesso em: 1 ago. 2018.

CANO, Ignácio et al. Impacto da Violência no Rio de Janeiro. Rio de Janeiro: Laboratório de Análise de Violência, UERJ, 2004.

Disponível em: <http://www.lav.uerj.br/docs/rel/2004/impacto_vio_ rio_2004.pdf>. Acesso em: 01 ago. 2018.

CHUEIRI, Vera Karam de. Agamben e o estado de exceção como zona de indeterminação entre o político e o jurídico. In: FONSECA, Ricardo Marcelo (Org.). Crítica da modernidade: diálogos com o Direito. Florianópolis: Fundação Boiteux, 2005.

CONSELHO DE DEFESA DOS DIREITOS HUMANOS. Resolução $\mathbf{n}^{\circ} \mathbf{0 8}$ de 21 dezembro de 2012. Disponível em: <http://www.mdh.gov.br/ informacao-ao-cidadao/participacao-social/old/cndh/resolucoes/2012/ resolucao-08-auto-de-resistencia>. Acesso em: 02 ago. 2018.

DESARMAMENTO segue no topo dos temas mais procurados pela sociedade. Jornal da Câmara dos Deputados, Brasília, DF, 8 out. 2015. Participação popular. Disponível em: http://www.camara.leg.br/internet/ jornalCamara/?date=2015-10-08. Acesso em 02.08.2018

SENTO-SÉ, J. T. L. O discurso brizolista e a cultura política carioca. Varia História, v. 18, n. 28, dez. 2002. Disponível em: <https://static1.squarespace. 
com/static/561937b1e4b0ae8c3b97a702/t/572b56e986db43e1a02f3e dd/1462458090415/06_Sento-Se\%2C+Joao+Trajano.pdf>. Acesso em: 09 nov. 2018.

SOARES, Francisca Vergínio. A política de segurança pública dos governos Brizola e Moreira Franco: à margem da Nova Violência. Rio de Janeiro: Papel Virtual, 2002.

MISSE, Michel et al. Quando a Polícia mata: homicídios por "autos de resistência" no Rio de Janeiro (2001-2011). Rio Janeiro: Booklink, 2013.

MISSE, Michel (Coord.). "Autos de Resistência": uma análise dos homicídios cometidos por policiais na cidade do Rio de Janeiro (20012011). Relatório Final de Pesquisa. Rio de Janeiro: Núcleo de Estudos da Cidadania, Conflitos e Violência Urbana da Universidade Federal do Rio de Janeiro, 2011.

VERANI, Sérgio. Assassinatos em nome da lei. Rio de Janeiro: Aldebarã, 1996. 